\title{
Molecular characterization of exon region of type 2 diabetes associated gene (KCNJ11) in Labrador retriever dogs
}

\author{
. \\ iD \\ P. Pranjali', P.D. Divya ${ }^{2 \star}$, J. Lijo ${ }^{3}$ and K.K. Jayavardhanan ${ }^{4}$ \\ Department of Veterinary Biochemistry, College of Veterinary \& Animal Sciences, \\ Mannuthy, Thrissur-680651, Kerala, \\ Kerala Veterinary and Animal Sciences University, Pookode, Wayanad, India.
}

Citation: Pranjali, P., Divya, P.D., Lijo, J., and Jayavardhanan, K.K. 2021. Molecular characterization of exon region of type 2 diabetes associated gene (KCNJ11) in Labrador retriever dogs.J. Vet. Anim. Sci. 52(1): 36-41. DOI: https://doi.org/10.51966/jvas.2021.52.1.36-41

Received: 03.11.2020

Accepted: 28.11.2020

Published: 01.01.2021

\begin{abstract}
The study was undertaken with the objective of characterization of the single exon region of potassium inwardly rectifying channel, subfamily J, member 11 (KCNJ11) gene in Labrador retriever breeds of dogs. The gene encodes the islet ATP-sensitive potassium channel Kir6. 2 which plays a major role in insulin secretion and is of substantial interest as a candidate gene for type 2 diabetes. The genomic DNA was isolated from six pedigreed Labrador retriever breeds of dogs and a 1173 bp fragment of the coding region of KCNJ11 gene was amplified by PCR technique using synthetic oligonucleotide primer pairs and the confirmation of PCR product was done by agarose gel electrophoresis. The PCR amplified products were purified and sequenced commercially. The sequenced data was compared with nucleotide sequences available in the data bank using suitable software. The nucleotide sequence showed 99 per cent homology between Labrador and Boxer breeds of dogs with two bases found to be replaced among the two sequences whereas, 100 per cent homology was observed between sequences of Labrador, Basenji and Great Dane dogs. Predicted amino acid sequence and the secondary protein structure revealed no characteristic change between the dog breeds suggestive of the highly conserved nature of the gene studied. The study can be extended in larger dog population to find out any polymorphism in the respective gene studied which might serve as a breed specific marker for screening diabetic dog population in future.
\end{abstract}

Keywords: Diabetes mellitus, Labrador retriever, KCNJ11 gene, kir 6.2 subunits, ATP-sensitive potassium channel

1. MSc Scholar

2. *Assistant Professor and corresponding author (email id: divyapd@kvasu.ac.in, Mobile: 9400651567)

3. Assistant Professor, Department of Veterinary Biochemistry, College of Veterinary \& Animal Sciences, Pookode, Wayanad

4. Professor \& Head

Copyright: () 2021 Pranjali et al. This is an open access article distributed under the terms of the Creative Commons Attribution 4.0 International License (http://creativecommons.org/licenses/by/4.0/), which permits unrestricted use, distribution, and reproduction in any medium, provided the original author and source are credited. 
Diabetes mellitus is a common endocrinopathy in companion animals, characterized by hyperglycemia and glycosuria, resulting from an absolute or relative deficiency or dysfunction of the pancreatic hormone insulin. It forms a major global public health problem in humans, and is also of great concern in dogs currently. Canine diabetes is a heterogeneous disease and, in majority of the cases, the underlying pathogenesis of the disease is not well established, although insulin deficiency is a consistent feature. The presence of certain diabetic phenotypes, along with specific breed predisposition to these different types of diabetes mellitus, suggests an underlying genetic basis for the disease susceptibility. This might vary from breed to breed with some breeds exhibiting greater susceptibility (Labrador retrievers, Dachshund etc.) while a few showing relative resistance (Boxer). Even though, canine diabetes mostly resembles type 1 diabetes, the involvement of type 2 diabetes is also reported particularly when the animals are overweight or when they are in dioestrous stage (Fall et al., 2007).

Many genes like KCNJ11, TCF7L2, GCK and SLC30A8 are associated with type 2 diabetes susceptibility but have received little attention to date with respect to canine diabetes (Catchpole et al., 2013). Among the different type 2 diabetes linked genes, KCNJ11 gene encodes the ATP-sensitive potassium (KATP) channel subunit Kir6.2, which play a major role in insulin secretion and is of substantial interest as a candidate gene for type 2 diabetes (Ashcroft, 2005). Mutations in KCNJ11 gene is associated with increased activity of the $\beta$ cell ATP-sensitive potassium channel, which account for the failure of glycaemic control during periods of hormone-induced peripheral insulin resistance, particularly when animals are overweight (Bonfanti et al., 2015). But the information regarding the involvement of this particular gene in the occurrence of canine diabetes is meager. Therefore, the study was undertaken with the objective of molecular characterization of single coding region of $K C N J 11$ gene in Labrador retriever breed of dogs, a breed more susceptible to type 2 diabetes; using PCR technique and its comparison with the nucleotide sequences available in the data bank. The present study also aims to analyze the predicted amino acid sequence and secondary protein structure of the exon region of the candidate gene with suitable online sequence analysis tools.

\section{Materials and Methods}

Blood samples were collected from pedigree dogs of Labrador retriever breed. Genomic DNA was isolated as per the standard protocols (Sambrook and Russel, 2001).

The primers targeting the $1173 \mathrm{bp}$ of the KCNJ11 gene of Labrador breed of dogs were designed using the Primer 3 software (www.bioinfo.ut.ee>primer3-0.4.0). The sequence of the KCNJ11 gene of Boxer breed of dogs available in the ensembl (Accession No. ENSCAFT00000013869) was utilized for designing primers. The suitability was checked with sequence manipulation suite software (www.bioinformatics.org>sms2) and specificity confirmed by blast analysis (BLASTn tool: www. ncbi.nlm.nih.gov).

The primer sequences used to amplify the coding region of $K C N J 11$ gene were

Forward (F1) - 5' TGCTGTCCCGAAAAGGCAT 3

Reverse (R1) - 5' AGGGAATCCGGAGAGATGCT 3

PCR conditions were standardized to minimize nonspecific amplification and to get maximum amplification of the desired product. Annealing temperature was standardized by performing gradient PCR. The optimum concentrations of various components obtained after standardization is shown below (Table 1.):

Table 1. Composition of PCR mix

\begin{tabular}{|l|l|}
\hline \multicolumn{1}{|c|}{ Components } & Volume \\
\hline 10X buffer with $\mathrm{MgCl}_{2}(15 \mathrm{mM})$ & $2.5 \mu \mathrm{L}$ \\
\hline dNTP $(2 \mathrm{Mm}$ each) & $3.0 \mu \mathrm{L}$ \\
\hline Forward primer $(20 \mathrm{pM} / \mu \mathrm{l})$ & $0.5 \mu \mathrm{L}$ \\
\hline Reverse primer $(20 \mathrm{pM} / \mu \mathrm{l})$ & $0.5 \mu \mathrm{L}$ \\
\hline Accu Taq DNA polymerase $(5 \mathrm{U} / \mu \mathrm{l})$ & $0.5 \mu \mathrm{L}$ \\
\hline Template DNA $(255.0 \mathrm{ng} / \mu \mathrm{L})$ & $2.0 \mu \mathrm{L}$ \\
\hline Nuclease free water & $16.0 \mu \mathrm{L}$ \\
\hline Total volume & $25 \mu \mathrm{L}$ \\
\hline
\end{tabular}


The reaction was carried out in a BioRad T100 Thermal Cycler using the following cycle parameters which was found to be optimal for the amplification of expected size of $1173 \mathrm{bp}$ shown in figure 1. A standard PCR protocol was used for amplifications, which consisted of an initial denaturation $95^{\circ} \mathrm{C}$ for $10 \mathrm{~min}, 34$ cycles for denaturation at $95^{\circ} \mathrm{C}$ for $1 \mathrm{~min}$, annealing at $55.5^{\circ} \mathrm{C}$ for $40 \mathrm{sec}$, extension at $72^{\circ} \mathrm{C}$ for 1 min and final extension at $72^{\circ} \mathrm{C}$ for $10 \mathrm{~min}$. The amplified products were electrophoresed at 70 $\mathrm{V}$ for $40 \mathrm{~min}$ in $0.8 \%$ agarose gel and visualized under UV light in a gel documentation system (Chemi doc MP). PCR products were purified and sequenced by Sanger's enzymatic DNA sequencing technique. The complete single coding sequence of KCNJ11 gene was assembled by joining the corresponding forward and reverse sequence fragments.

Various online and offline sequence analysis software and data bases were used to analyze the sequence obtained. The sequences were aligned using EMBOSS ( $w w w$. bioinformatics. $n>$ cgi-bin>merger) and blasted using NCBI BLAST tool (www.blast.ncbi.nlm. nih.gov $>$ blast) to analyze their similarity with other published sequences available in online databases. The obtained sequence were compared with the corresponding nucleotide sequence of different dog breeds available in the data bank by the multiple sequence alignment programme of ClustalW available at http:/www2. ebi.ac.uk/clustalw/. The aligned nucleotide sequences were subjected to phylogenetic analysis using the neighbor joining method of Clustal $\mathrm{W}$ to derive the ancestral relationship between different breeds. The translate tool of the sequence manipulation suite available at http:/www.bioinformatics.org/sms2/translate. $\mathrm{html}$, was used to translate the nucleotide sequence with a proper reading frame to the corresponding amino acid sequence. The secondary structure of the region containing the coding region was predicted using the Scratch protein predictor system (http://molbiol tools.ca/Protein_secondary_structure.html) of the institute for Genomics and Bioinformatics, University of California, Irvine, U.S.A. The amino acid sequences in one letter code were submitted for the structure prediction.

\section{Results and Discussion}

The KCNJ11 gene encodes Kir6.2 which is the pore forming subunit of the $\beta$-cell ATP-dependent potassium (KATP) channel which has attracted considerable attention as a promising candidate for type 2 diabetes because of its function as a key factor in the regulation of glucose-induced insulin secretion (Gloyn et al., 2004).

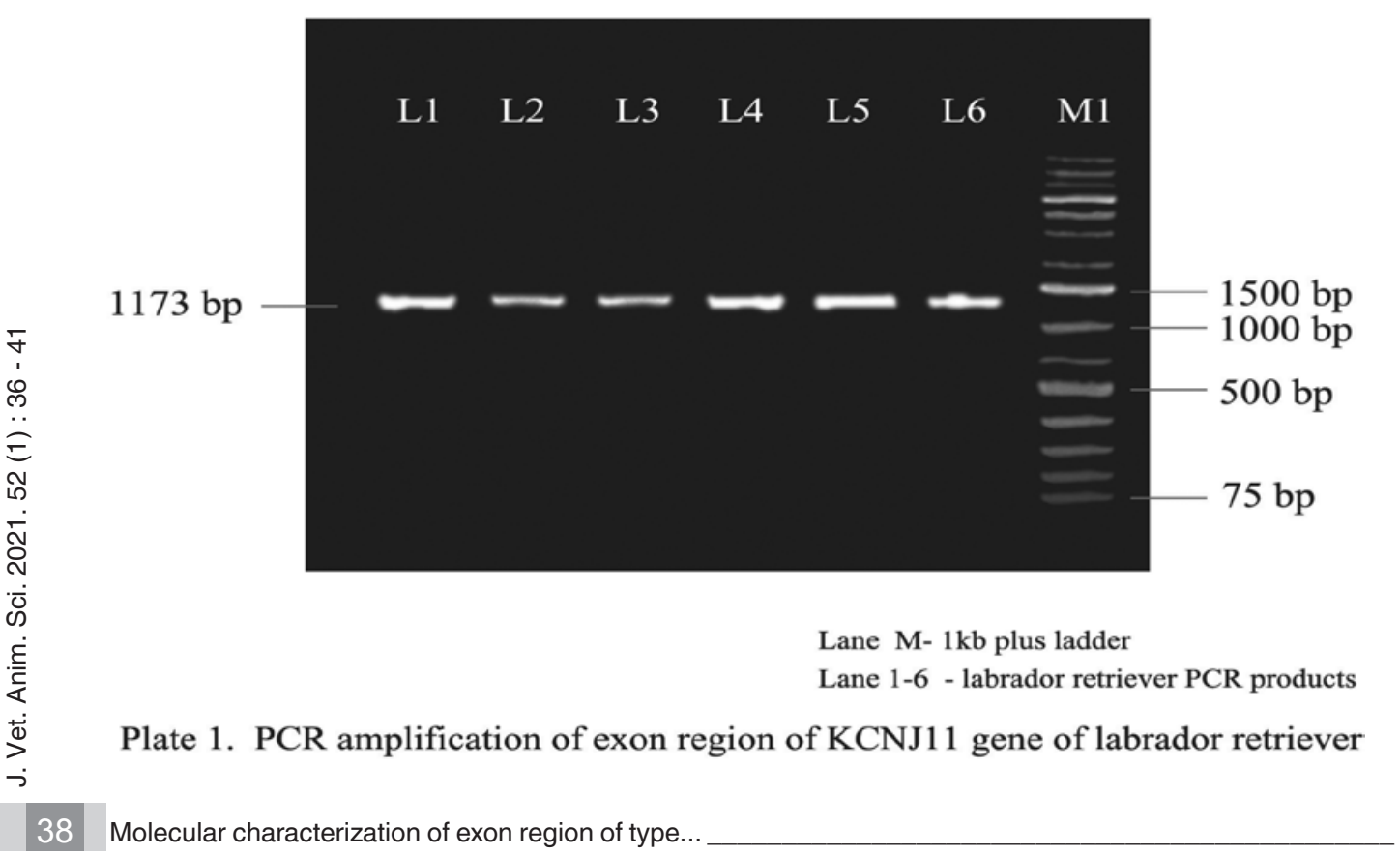




\begin{tabular}{|c|c|c|}
\hline Gr. Dane & GCCCCCGGTGAGGGCACTGCGGTGCCCTGTGT CACCAGCATCCACTCTTTTTCATCTGCC & 360 \\
\hline Basenji & GCCCCCGGTGAGGGCACTGCGGTGCCCTGTGTCACCA GCATCCACTCTTTTTCATCIGCC & 360 \\
\hline Boxer & GCCCCCGGTGAGGGCACTGCGGTGCCCTGTGTCACCA GCATCCACTCTTTT TCATCCGCC & \\
\hline \multirow[t]{2}{*}{ Labrador } & GCCCCCGGTGAGGGCACTGCGGTGCCCTGTGTCACCAGCATCCACTCTTTTTCATCIGCC & 19 \\
\hline & 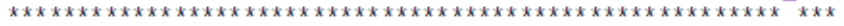 & \\
\hline Gr. Dane & TCCTTTTCTCCATTGAGGTCCAGGTGACCATTGGCTTTGGCGGGCGCATGGTGACCGAG & \\
\hline Basenji & TTCCTTTTCTCCATTGAGGTCCAGGTGACCATTGGCTITGGCGGGCGCATGGTGACCGAG & \\
\hline Boxer & TTCCTTT TCTCCATTGAGGTCCAGGTGACCAT TGGCTTTGGCGGGCGCATGGTGACCGAG & \\
\hline Labrador & TTCCTTTTCTCCATTGAGGTCCAGGTGACCATTGGCTITGGCGGGCGCATGGTGACCGAG & \\
\hline Gr. Dane & GAGTGCCCGCTGGCCATCTTGATCCTCATTGTGCAGAACATCGTGGGGCTCATGATCAAT & \\
\hline$n j i$ & GAGTGCCCGCTGGCCATCTTGATCCTCATTGT GCAGAACATCGTGGGGCTCATGA & \\
\hline Boxer & GAGTGCCCGCTGGCCATCTTGATCCTCATTGT GCAGAACATCGTGGGGCTCATGATCAAT & \\
\hline \multirow[t]{2}{*}{ Labrador } & GAGTGCCCGCTGGCCATCTTGATCCTCATTGTGCAGAACATCGTGGGGCTCATGATCAAT & \\
\hline & 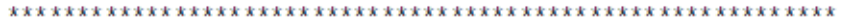 & \\
\hline Gr.Dane & GCCATTATGCTGGGCTGCATCTTCATGAAGACGGCCCAGGCCCATCGGCGGGCCGAGACC & \\
\hline Basenji & GCCATIATGCTGGGCTGCATCT TCATGA_AGACGGCCCAGGCCCATCGGCGGGCCGAGACC & \\
\hline Boxer & GCCATCATGCTGGGCTGCATCTTCATGA_AGACGGCCCAGGCCCATCGGCGGGCCGAGACC & \\
\hline Labrador & GCCATIATGCTGGGCTGCATCT TCATGAAGACGGCCCAGGCCCATCGGCGGGCCGAGACC & \\
\hline
\end{tabular}

Figure 1: Multiple sequence analysis of exon region of $K C N J 11$ gene

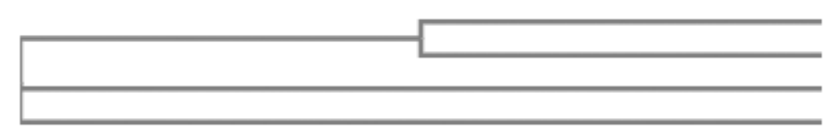

Gr.Dane -0.0001

Labrador 0.0001

Basenji -0.0001

Boxer 0.00222

Figure 2. Phylogenetic analysis of nucleotide sequence of exon region of $K C N J 11$ gene

\begin{tabular}{|l|l|}
\hline $\begin{array}{l}\text { Predicted amino } \\
\text { acid sequence }\end{array}$ & SPTVTWAPGEGTAVPCVTSIHSFSSAFLFSIEVQVTIGFGGRMVTE \\
& ECPLAILILIVQNIVGLMINAIMLGCIFMKTAQAHRRAETLIFSKH \\
& AVIAVRHGRLCFMLRVGDLRKSMIISATIHMQVVRKTTSPEGEVV \\
& PLHQVDIPMENGVGGNSIFLVAPLIIYHVIDANSPLYDLAPSDLHH \\
& HQDLEIIVILEGVVETTGITTQARTSYLADEILWGQRFVPIVAEEDG \\
& RYSVDYSKFGNTIKVPTPLCTARQLDEDRSLLD \\
\hline
\end{tabular}

Figure.3. Predicted amino acid sequence of exon region of $K C N J 11$ gene

The KCNJ11 gene has been shown to be highly polymorphic and is associated with permanent and neonatal diabetes (Vaxillaire et al, 2004).

The present study has been undertaken to analyze the KCNJ11 gene in Labrador retervier breed of dogs which are more prone to diabetes.

The single coding region of KCNJ11 gene was amplified using gradient thermal cycler with an optimum annealing at $55.5^{\circ} \mathrm{C}$. The size of the amplified products was confirmed by agarose gel electrophoresis (Thermo Scientific GeneRuler $1 \mathrm{~kb}$ plus DNA Ladder). Expected size of coding region of KCNJ11 gene was 1173 $\mathrm{bp}$ and the sequencing result revealed a size of $793 \mathrm{bp}$. The amplicons obtained had a size of $1173 \mathrm{bp}$ as shown in plate 1 . All the amplicons were purified and sequenced commercially at
AgriGenome Labs Private Limited, Kakkanadu, Ernakulam using Sanger's dideoxy nucleotide chain termination method.

The sequenced data was compared with the sequence available in the data bank using suitable software like multiple sequence alignment programme and phylogenetic analysis of Clustal W to find regions of local similarity between sequences. Translate tool of the sequence manipulation suite and Scratch protein predictor system were used to study the deduced amino acid sequences.

\section{Multiple Sequence Analysis}

To study sequence similarities, multiple sequence analysis was carried out between the sequences of Labrador retriever with nucleotide sequences of different dog breeds available in the data bank (Boxer-Access 
on \# ENSCAFT00000013869, Basenji Access on \# ENSCAFG00030024886 and Great Dane Access on \# ENSCAFG00040022090) downloaded from ensembl database. Nucleotide sequences of exon region of KCNJ11 gene exhibited 100 per cent identity between Labrador retriever, Basenji and Great Dane breeds of dogs whereas, only $99 \%$ identity was showed for boxer breed. Thymine $(\mathrm{T})$ was replaced by Cytosine $(\mathrm{C})$ in Boxer at two different positions when compared to that for Labrador, Basenji and Great Dane (Fig.1)

\section{Phylogenetic Analysis}

Phylogeneticanalysis of the nucleotide sequence of exon region of KCNJ11 gene in different dog breeds revealed clustering of Labrador and Great Dane breeds with Basenji and Boxer breed delineated themselves from other breeds by clustering out on a separate single branch from the main. Phylogenetic analysis of different dog breeds is shown in figure 2 .

\section{Amino Acid Sequence Analysis}

Even though, variations were noticed in the nucleotide sequence of exon region of KCNJ11 gene between Boxer breed and other three dog breeds including that for Labrador retriever breed of present study, the deduced amino acid sequences couldn't reveal any appreciablevariation(Fig.3).Theresultsuggests that the nucleotide sequence of $K C N J 11$ gene is highly conserved within a species (Sagen et al., 2004). Thus the present study, point out the significant role of the particular gene in regulation of insulin secretion from pancreatic $\beta$ cells thereby controlling blood glucose level. Differences in the breed prevalence of diabetes mellitus suggest that there are genetic factors that are involved in determining susceptibility to the disease (Andrea et al. 2007).

Some specific types of diabetes mellitus also seem to be breed related (Catchpole et al., 2013), there might be differences in the specific susceptibility genes that contribute to the overall genetic risk. As there are no previous reports on the molecular evidence of the role of $K C N J 11$ gene in canine diabetes, the study on nucleotide and amino acid sequence analysis would throw light on canine KCNJ11 gene architecture and the extent of functional and structural similarity with that of other dog breeds.

\section{Conclusion}

As type 2 diabetes is a multifactorial disorder where obesity plays a key role in its occurrence, the analysis of type 2 diabetes associated genes like KCNJ11 will pave the way in understanding this particular diabetic form. Considering the highly conserved nature of the KCNJ11 gene, polymorphism studies on this gene will shed light in screening the diabetic dog population in future. This would help to bridge the knowledge gap between the underlying pathophysiology and genetic basis of the disease and will help in development of interventional therapies.

\section{References}

Andrea, D. S., Catchpole, B., Kennedy, L. J., Barnes, A., Fretwell, N., Jones, C., Thomson, W. and Ollier, W.E.R. 2007. Analysis of Candidate Susceptibility Genes in Canine Diabetes. J. Hered. 98(5): 518-525.

Ashcroft, F. M., 2005. ATP-sensitive potassium channelopathies: focus on insulin Secretion. J. Clin. Invest. 115(8): 20472058.

Bonfanti, D. H., Alcazar, L. P., Arakaki, P. A., Martins, L. T., Agustin, B. C., DeMoraes Rego, F. G. and Friger, H. R. 2015. ATPdependent potassium channels and type 2 diabetes mellitus. Clin. Biochem. 48(7): 476-482.

Catchpole, B., Adams, J. P., Holder, A. L., Short, A. D., Ollier, W. E. and Kennedy, L. J. 2013. Genetics of canine diabetes mellitus: are the diabetes susceptibility genes identified in humans involved in breed susceptibility to diabetes mellitus in dogs? Vet. J. 195(2): 139-147.

Fall, T., Hamlin, H.H., Hedhammar, A., Kämpe, O., Egenvall, A., 2007. Diabetes mellitus in a population of 180,000 insured 
dogs: Incidence, survival, and breed distribution. J. Vet. Intern. Med. 21: 1209-1216.

Gloyn, A. L., Pearson, E. R., Antcliff, J. F., Proks, P., Bruining, G. J., Slingerland, A.S., Howard, N., Srinivasan, S., Silva, J.M., Molnes, J. and Edghill, E.L., 2004. Activating mutations in the gene encoding the ATP-sensitive potassium-channel subunit Kir6. 2 and permanent neonatal diabetes. N. Engl. J. Med. 350(18): 1838-1849.

Sagen, J.V., Reder, H., Hathout, E., Shehadeh, N., Gudmundsson, K., Bævre, H., Abuelo, D., Phornphutkul, C., Molnes, J., Bell, G. I. and Gloyn, A. L. 2004.
Permanent neonatal diabetes due to mutations in KCNJ11 encoding Kir 6. 2. Diabetes. 53(10): 2713-2718.

Sambrook, J. and Russel, D. W.2001. Molecular Cloning: A Laboratory Manual. Third edition. Cold Spring Harbor Laboratory Press, New York. 1886p.

Vaxillaire, M., Populaire, C., Busiah, K., Cavé, H., Gloyn, A.L., Hattersley, A.T., Czernichow, P., Froguel, P. and Polak, M. 2004. Kir6. 2 mutations are a common cause of permanent neonatal diabetes in a large cohort of French patients. Diabetes. 53(10): 2719-2722. 